\title{
SOCIOECOLOGY OF MARMOTS: FEMALE REPRODUCTIVE STRATEGIES ${ }^{1}$
}

\author{
Douglas C. Andersen, Kenneth B. Armitage, and Robert S. Hoffmann \\ Division of Biological Sciences, The University of Kansas, Lawrence, Kansas 66045 USA
}

\begin{abstract}
The relationship between female reproductive success and both spring food and hibernacula resources was examined in a high-altitude population of yellow-bellied marmots (Marmota flaviventris). The number of offspring a female weaned was significantly associated with the estimated number she could potentially produce, based on food resources. The production of young by these females is probably food limited to varying degrees. Hibernacula may be a restricted resource; young reared in an area without a hibernaculum were not recaptured as yearlings. Delaying pregnancy until forage is available fails as a strategy because young have insufficient time to accumulate fat for hibernation. Adult females deposit fat at a single maximum rate regardless of reproductive history; few females gain weight prior to weaning their young. In areas with short growing seasons, measured as the period during which nonreproductive adults gain weight, females may occasionally or regularly fail to reproduce in consecutive years. The short period of time following weaning may not permit the accumulation of fat sufficient to provide energy for hibernation, postemergence activity, and reproduction. The growth rate ( $\mathrm{g} /$ day) of young marmots is greater at high than at intermediate elevations. This increase in growth rate warrants further examination of the hypothesis that increased sociality among marmots living in areas with short growing seasons is a response to decreased growth rates of young animals.
\end{abstract}

Key words: Colorado; fat; food; growing season; growth rates; hibernacula; marmots; reproductive strategy.

\section{INTRODUCTION}

Yellow-bellied marmots (Marmota flaviventris) form colonies within favorable habitat, with one or more males each sharing its territory with one or more females (the harem) (Armitage 1962, 1965, 1973, 1974; Downhower and Armitage 1971; Svendsen 1974). Individual marmots may be broadly classified as aggressive, social, or avoider within an apparent continuum of behavioral profiles (Svendsen and Armitage 1973). Females may be social or solitary; individual reproductive success varies according to the social situation (Downhower and Armitage 1971, Svendsen 1974). All members of the genus Marmota hibernate; yellow-bellied marmots are active less than half of each year.

Two obvious habitat resources critical to reproductive success of yellow-bellied marmots are food and burrows. Although Downhower and Armitage (1971) postulated that limited food during gestation determined the reproductive success of females, marmots at $2,900 \mathrm{~m}$ in Colorado during gestation consumed only $1 \%-2 \%$ of the total available net primary production (Kilgore 1972). Armitage and Downhower (1974) suggested the number of available burrows did not affect the number of resident marmots within colonies, but could limit population size at the smaller satellite sites. They also noted large variations among years and among localities

${ }^{1}$ Manuscript received 30 April 1975; accepted 13 October 1975. in the percentages of young marmots recaptured as yearlings and attributed these differences in survival through hibernation to variation in winter conditions. Differences in survival could be affected by the quality of hibernacula and amount of fat accumulated for hibernation.

This study attempts to identify the environmental factors limiting the reproductive success of individual yellow-bellied marmots. The study was designed to examine three hypotheses concerning a high-altitude population, where environmental effects would be most pronounced; (1) that particular burrows, the hibernacula, are not a restricted resource; (2) that hibernacula do not vary in quality; and (3) that the reproduction by female yellow-bellied marmots is not food limited.

\section{Methods}

\section{Study area}

The study area (Fig. 1) is located in North Pole Basin in the Elk Mountains of west-central Colorado (Gunnison County; United States Geological Survey Snowmass Mountain quadrangle). The basin, $\approx 3 \mathrm{~km}$ long, is at most $1 \mathrm{~km}$ wide, encircled, except at the north end, by a ridge ranging in elevation from $3,680 \mathrm{~m}$ to $4,100 \mathrm{~m}$. The orientation of the basin affects the microclimates within those portions of the floor $(3,380 \mathrm{~m}$ elevation $)$ and lower sides making up the study area. Bedrock outcroppings with thinly developed soils bound the study area on the north and south, while stands of tall willow and krummholz 


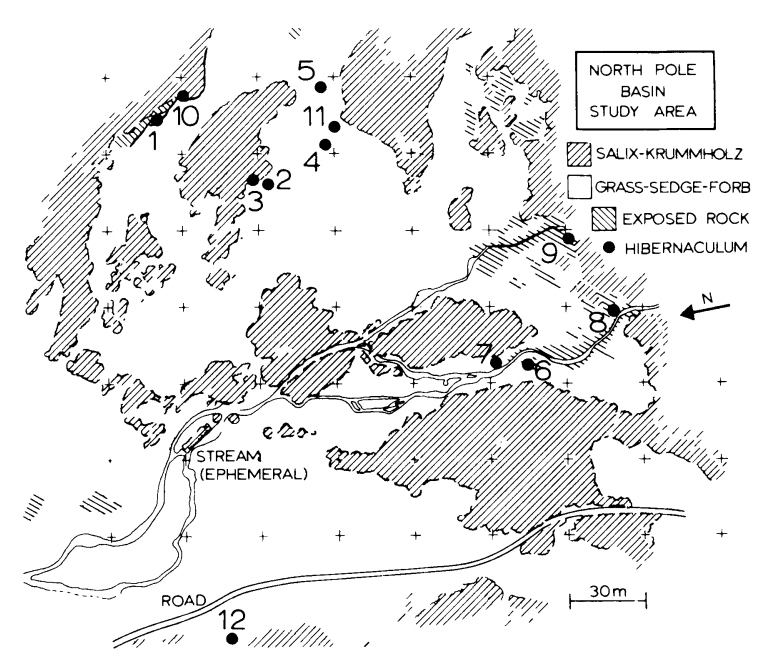

FIG. 1. North Pole Basin study area, showing locations of hibernacula. Hibernaculum 8 may be several hibernacula in close proximity, as several entrances were used independently throughout the summer. Hibernacula 1-7 were located by the presence of snow tunnels.

form the boundaries on the east and west. The resulting square of $\approx 7$ ha contained the hibernacula, summer burrows, and most of the home ranges of about 20 adult marmots.

The vegetation within the study area characterized a weakly developed "upland herb" community (Langenheim 1962) with typical alpine species in drier sites and local concentrations of snowflush and streamside species at wetter sites. Portions of the winter snowpack remained in the study area until the last week of July in 1974, and even later in 1973. An ephemeral stream (Fig. 1) disappeared into bedrock at the southern boundary of the study area by mid-August (1974), but reappeared as a continuously flowing spring $100 \mathrm{~m}$ downstream of the northern boundary. A listing of the plant species found in the study area is given in Andersen (1975).

\section{Observations and trapping}

Yellow-bellied marmots resident in the study area were trapped intensively from the third week of May through the first week of October 1974, in the manner described by Armitage (1974). Approximately every third day during the study period trapping was discontinued and continuous day-long observations were made to record location and activity of individual marmots at regular intervals. Data on the survival of young as yearlings were obtained from the 1974 May-to-August study period.

\section{Weights and growing season}

Marmots were weighed and released within a few minutes of each capture, allowing some individuals to be trapped repeatedly during a single day. In such cases, only the first weighing was included in the analyses. Fall 1973 weights were estimated from regression lines based on weights obtained earlier in that year. Minimum weights recorded during the 1974 active season were used as estimates of lean body weight. The difference between the minimum and highest weight was used as an estimate of the amount of body fat. Comparative data for East River Valley (16 km south, 2,900 m elevation) marmots were taken from weights collected between 1967 and 1973 (Armitage et al. 1976). Analysis of data included the use of biomedical programs (Dixon 1968) for regression analysis. Where appropriate, statistical tests are included in the text as the statistic ( $t$ or $F$ ), the degrees of freedom (df), and the probability level $(P)$, in the form ( $t$ or $F$, [df], $P$ ). Statistical significance was assumed as the $95 \%$ probability level throughout the analyses.

The length of the growing season in North Pole Basin was estimated from temperature data collected on a continuously recording hygrothermograph, from snowpack information collected as a series of photographs taken at approximately regular intervals, and from daily personal observation of local weather conditions.

\section{Food resources}

Preferred forage plants were determined by visually monitoring the free-ranging adults with the aid of a field telescope $(40-80 \times)$. Plants in which acceptance could not be verified were considered acceptable as forage in energy calculations. Food plant preferences reported in the literature (e.g., Pattie 1967, Downhower 1968) were not extended to this study because some of the reported food plants were not used by marmots in North Pole Basin. These differences may reflect food plant availability during foraging as well as intraspecific differences in palatability known to exist in some plants (Freeland and Janzen 1974).

The study area was divided into seven vegetation zones on the basis of cluster analysis performed on lists of species from 77 quadrats (each $1 \mathrm{~m}^{2}$ ) located randomly within the foraging areas (Sokal and Sneath 1963:185). Standing crop within each vegetation zone was estimated by clipping individual plant species within a $0.125-\mathrm{m}^{2}$ quadrat located inside each of the larger quadrats (Wiegert 1962). Preferred species were oven-dried $\left(60^{\circ} \mathrm{C}\right)$ to constant weight and their biomass determined (Andersen 1975). Quantitative sampling began 18 June, 90\% occurred after 23 June, and sampling was considered adequate by 12 July. The latter date was used to designate the end of the time period for which food resources were potentially limiting. After this period, food resources were in excess.

Energy values of whole shoots, leaves, or flowers 
were determined in a Parr $1411^{\circledR}$ semi-microcalorimeter and corrected for ash content determined by baking samples at $500^{\circ} \mathrm{C}$ for $4 \mathrm{~h}$ (Paine 1971). A single energy value was assigned to each plant species utilized or assumed acceptable to the marmots prior to 12 July (Andersen 1975). Both seasonal and spatial differences in the energy content of single species have been noted (Golley 1961, Bliss 1962, Hadley and Bliss 1964, Rochow 1969). The final energy value was in most cases (and in all cases involving common species) the average of several (2-18) values obtained from samples taken randomly within the study area. The effect of intraspecific variation of plants on the energy available within foraging areas is considered minimal.

Foraging areas expanded from near zero during and immediately following emergence to the size estimated to be available to the individual females by 12 July. The accompanying increase in available energy was provided for by weighting portions of each foraging area, defined by a series of five contours outlining progressive snowmelt, according to the proportion of days, between emergence and 12 July, that those areas were snow-free. Overlapping foraging areas were treated by dividing the area of overlap equally among all users.

\section{Energy required for production of young}

The quantity of energy each adult female in the study area would have required to produce one young was calculated using equations developed by Kilgore (1972). For example, Kilgore found that digestive efficiencies of adult females vary with season (time of year) and body size; thus female $143 \mathrm{had}$ an average digestive efficiency of $62 \%$, and female $192,55 \%$. We assumed that birth weight of yellow-bellied marmots was equal to the $27 \mathrm{~g}$ reported for M. monax (Snyder et al. 1961) and that linear growth of young occurred during each of the 30-day periods presumed necessary for gestation and lactation. Young probably were observed the first day they emerged from their natal burrow, and all were weighed within a few days of first sighting. Hence, these weights are an estimate of size at weaning. Because the mean weight of male young ( $464 \mathrm{~g}, n=20$ ) was not significantly different $(t=1.25, \mathrm{df}=31, p<0.90)$ from that of female young ( $419 \mathrm{~g}, n=13$ ), a pooled estimate of the mean weight of young marmots $(446 \mathrm{~g})$ was used. Thus we estimated that during gestation young grew at a rate of $(27 / 30)=0.9 \mathrm{~g} /$ day, and during lactation $(446-27) / 30=14.0 \mathrm{~g} /$ day.

The date of conception for each female, and thus the degree of development $(=$ cost $)$ of her offspring by 12 July, was estimated by subtracting 60 days from the date her young were first observed. For females whose mammae and weight data suggested that litters were started but lost, conception dates were extrapolated from those estimated for other members of the same harem.

A litter size of six was selected as the maximum which could be attained by all adult females in the study area. While this number is not critical to the analysis, six represents a high but common value reported for litter sizes (Nee 1969, Downhower and Armitage 1971) and as such serves as a realistic reference point. A female was considered to be food limited if the energy within her foraging area was insufficient to allow her to carry a litter of six young to 12 July. For example, if a female produced three young, she was considered food limited if the energy available to her was insufficient for production of an additional three young. We stress here that finding individual females to be food limited does not imply that the population was food limited, nor does such a finding imply anything concerning the carrying capacity of the environment.

\section{RESUlts \\ Hibernacula}

Up to 20 adult females may have hibernated within the study area during the winter of 1973-74. Seven hibernacula (Fig. 1) were identified by the presence of snow tunnels. Five additional burrows located in rock outcroppings where marmots were active during the emergence period were considered hibernacula. The sole use of a hibernaculum by an adult female was established in one case, and suspected in several others; however, most females shared the hibernaculum with another adult female. In two cases, three females may have shared the same hibernaculum. Agonistic encounters between females and between males were observed during the study, but no unambiguous overt defense of hibernacula per se was established. All territorial males shared their hibernacula, both in 1973-74 and 197475 , with one or more adult females. For each of the three males having all or most of their territory within the study area, the most commonly used summer burrow was also the hibernaculum both winters. The hibernaculum was thus the focal point of each male's territory for most of the summer. All hibernacula found within the study area were within a male's territory throughout the summer. Three resident females did not use their hibernaculum as their principal summer burrow.

If hibernacula differ in factors affecting the rates at which marmots within them expend energy while hibernating, then variation in the amounts of fat used by hibernating marmots should be greater between, rather than within, hibernacula. A comparison of the hibernating costs of adult females associated with different hibernacula was inconclusive (Table 1). Data were available for only two animals 
TABLE 1. Estimates of the amounts of fat stored and utilized by North Pole Basin $q q$ from one active season into the next (through the winter 1973-74)

\begin{tabular}{|c|c|c|c|c|c|c|c|}
\hline \multirow{4}{*}{$\begin{array}{c}\text { Female } \\
\text { No. }\end{array}$} & \multirow{4}{*}{$\begin{array}{c}\text { Lean } \\
\text { weight } \\
(\mathrm{kg})\end{array}$} & \multicolumn{5}{|c|}{ Season } & \multirow{4}{*}{$\begin{array}{c}\text { No. of } \\
\text { young } \\
\text { produced }\end{array}$} \\
\hline & & \multirow{3}{*}{$\begin{array}{c}\text { Fall } \\
\text { Total fat } \\
\text { stored prior to } \\
\text { hibernation } \\
(\mathrm{kg})\end{array}$} & \multirow{2}{*}{\multicolumn{2}{|c|}{ 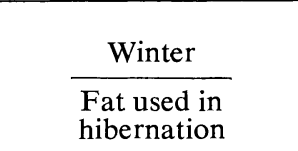 }} & \multirow{2}{*}{\multicolumn{2}{|c|}{$\begin{array}{l}\text { Spring } \\
\text { at utilized in } \\
\text { roduction and } \\
\text { maintenance }\end{array}$}} & \\
\hline & & & & & & & \\
\hline & & & $\mathrm{kg}$ & $\%$ total & $\mathrm{kg}$ & $\%$ lean wt. & \\
\hline 173 & 2.4 & 2.4 & 1.7 & $71 \%$ & 0.7 & $29 \%$ & 0 \\
\hline 175 & 2.4 & 2.4 & 2.0 & $83 \%$ & 0.4 & $17 \%$ & NR \\
\hline $143^{a}$ & 2.7 & 1.8 & 1.7 & $94 \%$ & 0.1 & $4 \%$ & $5(4-6)$ \\
\hline $192^{a}$ & 3.3 & 1.5 & 1.5 & $100 \%$ & 0.0 & & $5(4-6)$ \\
\hline $184^{\mathrm{b}}$ & 1.8 & 0.9 & 0.9 & $100 \%$ & 0.0 & & 3 \\
\hline $183^{\mathrm{b}}$ & 1.8 & 0.7 & 0.5 & $71 \%$ & 0.2 & $11 \%$ & 0 \\
\hline $257^{\mathrm{b}}$ & 2.1 & 0.9 & 0.8 & $89 \%$ & 0.1 & $5 \%$ & NR \\
\hline
\end{tabular}

${ }^{\text {a }}$ Hibernated together.

b 2 -yr-olds.

$\mathrm{NR}=$ nonreproductive.

known to have hibernated together. Both expended relatively low amounts of fat and eventually produced large litters, which might be interpreted as due to a high quality hibernaculum. However, confounding factors may also explain the large litter sizes (see below). Variation between age classes is likely due to factors related to maturity or size.

\section{Food resources}

The energy available from preferred vegetation within each adult female's effective foraging area varied from $5,732 \mathrm{~kJ}$ to $157,193 \mathrm{~kJ}$ (1,370 to 37,570 kcal) (Table 2). Yellow-bellied marmots do not breed as yearlings and only $25 \%$ of the 2-yr-old females produce litters (Armitage and Downhower

TABLE 2. Real and potential reproductive success of adult $q$ in North Pole Basin. Energy available is a measure of net primary production, through $12 \mathrm{July}$, of preferred vegetation within each $q$ 's foraging area, modified for snowmelt patterns and overlapping home ranges. The percentage of each foraging area not shared with other $\circ \%$ is 100 minus the sum of the values in the table. To convert kilocalories to kilojoules ( $\mathrm{kJ}$ ), multiply by 4.184

\begin{tabular}{|c|c|c|c|c|c|c|c|c|c|c|}
\hline \multirow{3}{*}{$\begin{array}{c}\text { Female } \\
\text { No. }\end{array}$} & \multirow[b]{3}{*}{ Age } & \multirow{3}{*}{$\begin{array}{c}\text { Date } \\
\text { young } \\
\text { weaned }\end{array}$} & \multirow{3}{*}{$\begin{array}{c}\text { A } \\
\text { No. } \\
\text { weaned y } \\
\text { young } \\
\text { emerging }\end{array}$} & \multirow{3}{*}{$\begin{array}{l}\text { No. } \\
\text { yearlings } \\
\text { recap- } \\
\text { tured }\end{array}$} & \multirow{3}{*}{$\begin{array}{l}\text { B } \\
\text { Cost per } \\
\text { young } \\
\text { carried to } \\
12 \text { July } \\
\text { (kcal) }\end{array}$} & \multirow{3}{*}{$\begin{array}{c}\text { C } \\
\text { Energy } \\
\text { still } \\
\text { available } \\
\text { (kcal) }\end{array}$} & \multirow{3}{*}{$\begin{array}{l}\text { Potential } \\
\text { reproductive } \\
\text { success to } \\
12 \mathrm{July} \\
\mathrm{A}+(\mathrm{C} / \mathrm{B})\end{array}$} & \multicolumn{3}{|c|}{ Foraging area } \\
\hline & & & & & & & & \multirow{2}{*}{$\begin{array}{l}\text { True } \\
\text { size } \\
\left(\mathrm{m}^{2}\right)\end{array}$} & \multicolumn{2}{|c|}{$\begin{array}{l}\text { Percent shared } \\
\text { with other } \\
\text { females }\end{array}$} \\
\hline & & & & & & & & & $\overline{w / 1}$ & $w />2$ \\
\hline $185^{\mathrm{a}}$ & $>3$ & $20 \mathrm{Jul}$ & 6 & 3 & 5,144 & 7,359 & $>6$ & 1,742 & 15 & 3 \\
\hline $248^{\mathrm{a}}$ & $>3$ & $27 \mathrm{Jul}$ & 6 & 6 & 3,947 & 5,472 & $>6$ & 2,305 & 10 & 85 \\
\hline $187^{a}$ & 3 & 5 Aug & 1 & 1 & 1,789 & 1,371 & 1 & 680 & 42 & 45 \\
\hline $139^{a}$ & $>3$ & 11 Aug & 3 & 0 & 415 & 6,519 & $\gg 6$ & 1,103 & 80 & 0 \\
\hline $173^{a, b}$ & $>3$ & & 0 & & $3,328^{\mathrm{c}}$ & 8,919 & 2 & 3,627 & 32 & 46 \\
\hline 175 & $>3$ & & NR & & $2,341^{\mathrm{c}}$ & 5,130 & 2 & 1,492 & 52 & 0 \\
\hline 141 & $>3$ & $16 \mathrm{Jul}$ & 3 & 3 & 5,735 & 6,718 & 4 & 980 & 37 & 0 \\
\hline $143^{\mathrm{d}}$ & $>3$ & $17 \mathrm{Jul}$ & $5(4-6)$ & 0 & 5,532 & 6,190 & 6 & 2,586 & 79 & 16 \\
\hline $192^{\mathrm{d}}$ & $>3$ & $17 \mathrm{Jul}$ & $5(4-6)$ & 0 & 6,487 & 32,342 & $\gg 6$ & 6,768 & 42 & 12 \\
\hline 431 & $\geqslant 3$ & & NR & & $\mathrm{NC}$ & $37,571 \dagger$ & & 3,707 & 21 & 0 \\
\hline 184 & 2 & 6 Aug & 3 & 1 & 1,149 & 14,010 & $\gg 6$ & 2,316 & 17 & 3 \\
\hline $183^{b}$ & 2 & & 0 & & $2,773^{c}$ & $2,836 \ddagger$ & $1-2$ & $1,459 \ddagger$ & 9 & 90 \\
\hline 257 & 2 & & NR & & $\mathrm{NC}$ & $9,430 \neq$ & -- & $3,784 \ddagger$ & 28 & 33 \\
\hline
\end{tabular}

${ }^{\mathrm{a}}$ Indicates females whose complete foraging areas were inside the study area for which estimates of both (B) and (C) have minimal error.

${ }^{b}$ Started but lost litters.

c Values of (B) were calculated using conception time of burrow mates.

d Shared the same burrow, and together produced 10 young; 4-6 represents the most likely litter size for each.

$\mathrm{NR}=$ nonreproductive; evidence of having started litters. $\mathrm{NC}=$ conception time could not be calculated.

$\dagger$ This estimate of available energy is accurate; however, female 431 was not observed inside the study area prior to 23 June.

$¥$ Indicates minimum estimate due to probably foraging outside the study area; actual values may be $50 \%-100 \%$ higher. 


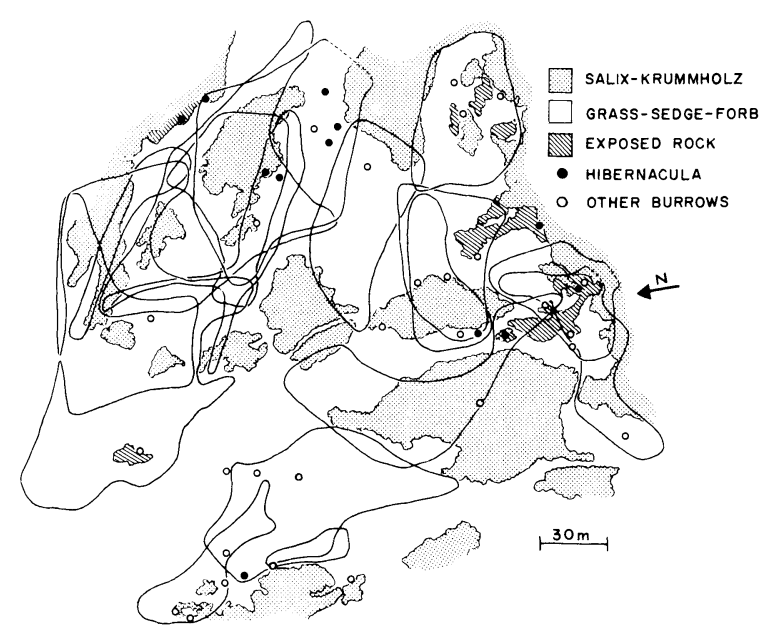

FIG. 2. Foraging areas of adult $q 9$ through 12 July. Open circles are auxiliary and home burrows used during the 1974 active season.

1974). Woodchucks (Marmota monax) breeding as yearlings produce smaller litters than older females (Snyder and Christian 1960). Because the litters of the 2-yr-old females may reflect age-specific effects, or factors related to primiparity, these animals were not considered in the following analyses.

There is a significant relationship between the number of young emerging above ground and the potential number of young a female could have produced on the basis of available energy for the first six females of Table 2 (Olmstead and Tukey's corner test for association; $0.05>p>0.02$; Sokal and Rohlf 1960:539). The same trend is reflected among the remaining females, although significance cannot be determined. We conclude that the females are food limited to varying degrees. This conclusion assumes that these females are unaware of limiting factors that may affect their potential reproductive success and do not adjust their foraging areas accordingly. The validity of the qualifying assumption is supported by the apparent initiation but subsequent loss of litters by at least two females. The loss of litters is inferred from the physical development of the mammae in preparation for lactation, and weight drops either prior to or near the time harem mates underwent parturition, followed by an almost immediate attainment of the maximum rate of weight gain. Also, most females could increase the energy available to them only through encroachment into neighboring foraging areas. The expanding home ranges of the females left few portions of the study area unexploited by 12 July (Fig. 2). Areas not used were typically those flooded by runoff during the period of intense snowmelt following the last spring snowstorm (5-8 June), or which contained dense concentrations of Geum rossii, a plant relatively common but never observed to be utilized.

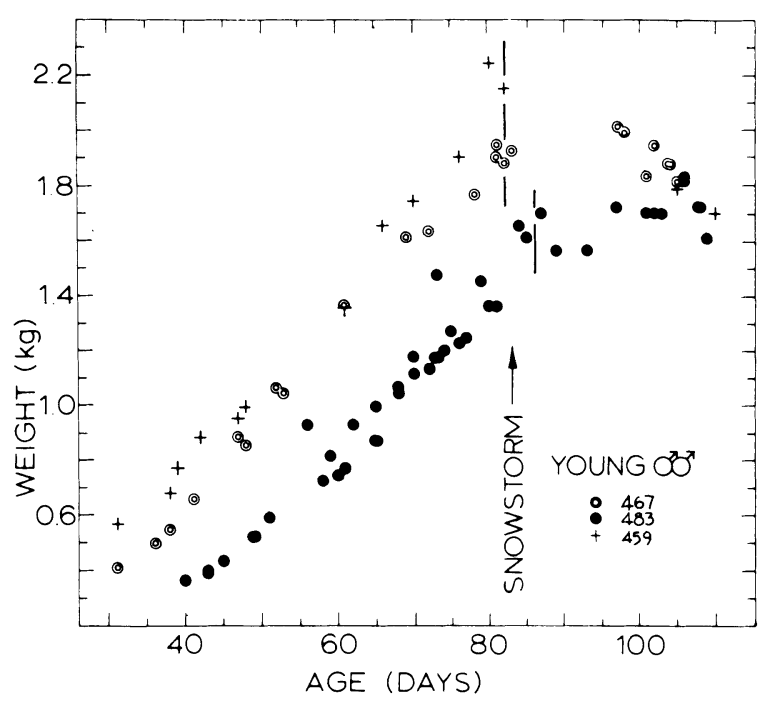

FIG. 3. Scatter diagrams of weight data for three young from North Pole Basin. Age is based on first sighting at age 30 days ( $=$ age at weaning). Linearity of growth prior to the snowstorm (12 September) was typical of all young and adult $q$ o during period of growth. Mothers of 467,483 , and 459 , were 185,248 , and 192 or 143 , respectively.

\section{Growth rates of young}

Young in the North Pole Basin study area showed linear growth prior to the 12 September snowstorm which generally terminated growth (Fig. 3). Only weights obtained before 12 September were included in the analysis of growth rates. For East River Valley young, only weights obtained prior to 15 September were utilized (Armitage et al. 1976).

No significant differences in the rate of weight gain $(\mathrm{g}$ /day) were found among 18 of the 20 male young (Table 3$)$ born in the study area $(F=1.49$ $[17,179] P \cong 0.90)$. One male gained weight significantly faster $(F=1.73[18,189] P>0.95)$, and another, significantly slower. The latter was found dead with no apparent external injuries in midAugust (about 90 days old), suggesting disease, congenital defect, or internal injury, any one of which could result in the low weight gain observed. No significant differences were found in the rate of weight gain among nine of the ten female young emerging within the study area $(F=1.46[8,73]$ $P<0.90$ ). One female (Table 3 ) grew exceptionally fast $(F=3.46[9,84] P>0.99)$, at a rate comparable to most young males.

Groups of ten male and ten female young from the East River Valley population had significant differences among individual patterns of weight gain ( ㅎㅇ of : $F=5.54[9,27] P>0.99$; 우 우: $F=3.21$ $[9,25] P>0.975)$. However, removal of only one female with a significantly low growth rate and two males with significantly higher growth rates (Table 
TABLE 3. Rates of weight gain ( $95 \%$ confidence interval) for young yellow-bellied marmots from high (3,380 $\mathrm{m})$ and intermediate elevation $(2,900 \mathrm{~m})$ sites. Common rates are obtained as the weighted average of the slopes of those animals showing no significant within-group differences in weight gain rate (Snedecor 1956:398). $n=$ number of marmots, $N=$ total number of weighings

\begin{tabular}{|c|c|c|c|c|c|c|}
\hline \multirow[b]{2}{*}{ Site } & \multirow[b]{2}{*}{ Sex } & \multicolumn{3}{|c|}{ Common } & \multicolumn{2}{|c|}{ Individual } \\
\hline & & g/day & $n$ & $N$ & g/day & $N$ \\
\hline \multicolumn{7}{|l|}{ North Pole } \\
\hline \multirow[t]{2}{*}{ Basin } & $\hat{o} \hat{o}$ & $29.3 \pm 0.9$ & 18 & 195 & $\begin{array}{l}32.9 \pm 2.7 \\
19.3 \pm 5.5\end{array}$ & $\begin{array}{l}12 \\
10\end{array}$ \\
\hline & q 9 & $23.8 \pm 1.3$ & 9 & 91 & $30.8 \pm 3.6$ & 13 \\
\hline \multicolumn{7}{|l|}{ East River } \\
\hline \multirow[t]{2}{*}{ Valley } & $\hat{o} \hat{o}$ & $16.8 \pm 2.1$ & 8 & 37 & $\begin{array}{l}27.4 \pm 2.4 \\
26.4 \pm 13.4\end{array}$ & $\begin{array}{l}6 \\
4\end{array}$ \\
\hline & 우우 & $19.4 \pm 1.7$ & 9 & 40 & $13.0 \pm 1.3$ & 5 \\
\hline
\end{tabular}

3 ) resulted in the remaining within-group differences becoming insignificant at the 0.90 level ( $\delta$ s $\delta: F=$ $1.43[7,21]$; $ᄋ$ \% : $F=1.80[8,22])$. Examination of the records for these individuals indicated nothing to justify their exclusion from the analysis a priori.

The rate of weight gain, based on the common regression estimates, is significantly greater at the higher elevation ( ô ô : $F=117.8[1,222] P>0.99$; 우 우 $F=62.6[1,96] P>0.99)$. The two fastgrowing males from East River Valley grew as fast as the grouped males of North Pole Basin ( $F=1.50$ [19, 185] $P \cong 0.90$ ), however, all ten males from East River Valley have a common regression estimate $(20.4 \pm 1.8)$ significantly below that of the North Pole Basin group of 18 males $(F=84.5[1,258]$ $P>0.99$ ).

\section{Adult female growth rates}

No female in the North Pole Basin study area gained weight significantly during lactation; only one gained weight during gestation which would be expected simply as a result of the increasing weight of the developing young. Thus, in order for females producing litters to accumulate summer fat stores comparable to those accumulated by nonreproductive females, they would have to either accumulate fat for a longer period of time, or at a faster rate. The onset of hibernation varied among the females within the study area and timing of hibernation was not correlated with reproductive history. In addition, the first major fall snowstorm (12 September) probably terminated weight gain for all adult females regardless of their fat accumulation or fall activity patterns. Only three adult females, including two who had litters, could be examined for weight changes subsequent to the storm; all lost weight. Two females, one of which produced a litter, lost weight at highly significant rates $(P>0.99)$. Seven adult females had adequate numbers of weighings prior to the fall storm to allow comparison of rates of weight gain ( $=$ fat deposition). The rates of weight gain for six of the seven females were not significantly different (Table 4), although they had various reproductive histories. The growth rates of three additional females were equal to or higher than these six, but confidence limits could not be established. One female marmot had a growth rate significantly lower than the rest.

\section{Discussion}

If hibernacula are a limited resource, all adult females should either include a hibernaculum in areas within which they have exclusive use (nonsocial animals) or they should freely associate with females who would share an accessible hibernaculum (social animals). Females within our study area fit both patterns. Because breeding occurs shortly after emergence (Armitage 1965, Nee 1969) and travel during this period is extremely limited (Armitage 1965, Armitage and Downhower 1974), the number of females hibernating within a male's territory is proportional to his potential reproductive success. Thus male yellow-bellied marmots should include all possible hibernacula within their territories. This

TABLE 4. Rates of weight gain (95\% confidence interval) for adult $q$ ㅇ having various reproductive histories, examined during the period of maximum fat deposition. Weight data and mammary development suggest $q$ 우 173 and 183 terminated pregnancy at or before the onset of lactation. The first six o $q$ have rates not significantly different from one another $(F=1.96$ $[5,43] p<0.90$ ); the common rate (see Table 3 ) for that group is $28.3 \pm 2.0 \mathrm{~g} /$ day. $\mathrm{NR}=$ nonreproductive

\begin{tabular}{ccccc}
\hline \hline $\begin{array}{c}\text { Female } \\
\text { number }\end{array}$ & $\begin{array}{c}\text { Litter } \\
\text { size }\end{array}$ & $\begin{array}{c}\text { Period } \\
\text { examined }\end{array}$ & $\begin{array}{c}\text { Rate of } \\
\text { weight gain } \\
\text { (g/day) }\end{array}$ & $\begin{array}{c}\text { No. of } \\
\text { weighings }\end{array}$ \\
\hline 185 & 6 & post-lactation & $33.4 \pm 9.0$ & 10 \\
173 & 0 & post-termination & $29.9 \pm 6.2$ & 9 \\
175 & NR & entire & $28.7 \pm 2.7$ & 9 \\
184 & 3 & post-lactation & $21.0 \pm 8.5$ & 12 \\
183 & 0 & post-termination & $32.7 \pm 26.5$ & 5 \\
257 & NR & entire & $27.5 \pm 1.7$ & 10 \\
248 & 5 & post-lactation & $9.5 \pm 15.7$ & 10 \\
\hline
\end{tabular}


pattern was evident in North Pole Basin. These lines of evidence are consistent with the hypothesis that hibernacula are a restricted resource and may limit the reproductive success of individual females.

The most pronounced effects of any variation in the quality of hibernacula might be among young marmots hibernating for the first time. The survival of young is significantly correlated with the termination of their first winter (Armitage and Downhower 1974). Such differential mortality among hibernating young may derive from inadequate fat stores caused by differential access to food resources during the previous active season. Access varies because young generally forage only in areas either utilized by or accessible to their mothers. The general uniformity of the growth rates of North Pole Basin young (Table 3 ) suggests that such differential access does not contribute to overwinter survivorship of young. Thus, it seems important that the female's reproductive strategy should include access by her young to a hibernaculum.

Few females produced the maximum number of young calculated as possible on the basis of their plant-food energy resources (Table 2). These calculations neglect conditions existing immediately after emergence. Females for whom the numbers of weighings were adequate lost weight from the time of emergence through 8 June, the last day of a 4-day spring snowstorm. Additionally, we observed female marmots active in areas that did not provide forage for a considerable period after emergence and no animal was seen to attempt the lengthy and presumably dangerous trips necessary to obtain forage available in those areas where snowmelt had preceded the resident's emergence or arrival. These observations and the general inability to gain weight prior to parturition suggest that parous females utilize body fat remaining after hibernation as a source of energy during the initial stages of reproduction, as woodchucks do (Snyder et al. 1961).

If females are limited not only by forage but also by spring fat reserves, a positive correlation should exist between the number of young produced above ground and a female's probable fat stores remaining upon emergence. The trend is negative (Table 1), suggesting that spring fat stores are detrimental to reproductive success. This paradox is resolved by considering individual reproductive strategies. If fat reserves are inadequate for reproduction, two options are open to a reproductive female. She can either move to an area in which forage becomes available early, or she can delay pregnancy until food becomes available within nearby areas. Both strategies minimize the dependence on spring fat reserves for reproduction and both were utilized by the females producing litters.

Females 143 and 192 were two of the three females resident on the study area who did not utilize their hibernaculum as a summer residence burrow. Although these two hibernated together, they independently abandoned the hibernaculum soon after emergence in late May. By 4 June, they had rejoined and were utilizing an area $100 \mathrm{~m}$ from the hibernaculum, the first area within the study site not already harboring marmots to become snow-free. The young of females 184 and 139 were the last to appear within the study area (Table 2). Thus their gestation occurred as forage became readily accessible within their foraging areas.

Although females 143 and 192 had high litter sizes, their reproductive success was not commensurate. None of the young of these females was recaptured as a yearling in 1975 (Table 2). Their strategy gambled short-term success, measured in numbers of young produced, against long-term reproductive success measured as the number of yearlings produced (Downhower and Armitage 1971). Females 143 and 192 subsequently appeared to have difficulty in re-establishing access to their previous hibernaculum; the location of their hibernacula the second winter is uncertain. Their young did not follow them into the area containing the previous year's hibernaculum, possibly because of the agonistic behavior shown towards them by other adult females utilizing the area. These young wandered unusually widely in late September presumably searching for a hibernaculum. Several of them probably hibernated in a burrow not identified as a hibernaculum. We attribute the loss of these young to their inability to obtain a suitable hibernaculum.

Females 184 and 139 and their young had little time following weaning to accumulate fat for hibernation. Over-winter mortality of small young ranges from $75 \%$ to $90 \%$ (Armitage et al. 1976). Although both females survived, only one of five young that hibernated (one young was cannibalized by an adult female) survived. Thus the strategy of delaying pregnancy until forage increases has severe limitations.

Large spring fat stores alone do not guarantee large litters. Female 173 had the largest fat reserves, but failed to wean a litter (Table 1). Food may have been insufficient (Table 2) following depletion of her fat reserves to adequately maintain the litter she probably started.

Female woodchucks (M. monax) use fat during the spring breeding season (Snyder et al. 1961), but data on the success of individual females are lacking. The loss of weight by our marmots following emergence from hibernation testifies to the importance of fat reserves. The quantity of fat in spring is a function of the total amount stored the previous fall and the amount utilized during hibernation. The optimal strategy for the individual female would 
thus be to maximize the quantity of fat stored by fall and to minimize the use of fat during hibernation (select the best hibernaculum).

Because growth rate usually is maximized regardless of reproductive history (Table 4), the rate of weight gain cannot be the principal factor determining the size of fall fat deposits. The critical factor is the total length of time during which weight gain is possible. Those animals with the longest period of weight gain prior to hibernation will have the largest absolute amounts of fat. Females conceiving early in the spring will, in this respect, have an advantage because of the greater length of time available for fat deposition after weaning. However, early conception and/or early emergence from hibernation increase utilization of fat in maintenance and reproduction. Thus there is a strict limitation on the strategy of early emergence and early conception. Most females probably emerge and reproduce as early as possible (Armitage 1965, Nee 1969) and most depend on the post-weaning period to obtain adequate nutrition for hibernation and reproduction. At high elevations, the post-weaning growth period may not be sufficient to allow both survival through hibernation and reproduction. None of the 28 tagged females who were resident two or more years in our North Pole Basin study area has bred in successive years. By contrast, many females in the East River Valley breed annually.

Barash $(1973 a, 1974 b)$ suggested that the gradient of sociality observed among species of Marmota is the result of a necessity to inhibit early dispersal and to closely regulate population size in severe environments. Predictions generated by his hypothesis were supported by studies examining social behavior of hoary marmots ( $M$. caligata) and of yellowbellied marmots (Barash 1973b, 1974a). A critical feature of the evolutionary scheme proposed by Barash is that young animals have retarded growth rates resulting from the decrease in growing season associated with harsh climates.

One factor which confounds the analysis of Barash's hypothesis is the determination of the length of the growing season. We used four criteria for estimating the 1974 growing season in North Pole Basin. The most significant estimate would seem to be the period during which positive weight gain occurred. In our study area that period of 96 days from 8 June to 12 September coincided with our second criterion, the period free of major snowstorms. Neither of our other two criteria, the longest frost-free period (60 days) and period free of snowpack (100 days from 25 June to 3 October) accurately reflected the marmot growing season. Barash (1973a:236) estimated the vegetative growing season experienced by Olympic marmots at 35-75 days, but his growth curves show marmots gaining weight for up to 120 days, 24 days more than in North Pole Basin.

In contrast to Barash's suggestion that young animals have retarded growth rates at the higher elevations, our young had higher growth rates than both yellow-bellied marmots at lower elevations (120 days growing season) (Table 3) and young male Olympic marmots (3 g/day) with a longer growing season (Barash 1973a: Table 1). These differences imply that different selection pressures are adjusting the reproductive strategies of these two species. Thus an evolutionary model of marmot sociality based on universal selection pressures focused on retarded growth rates is invalid.

More attention should be given to the role of hibernacula availability as a factor in the evolution of marmot societies. The distribution, abundance, and quality of hibernacula may vary both locally and regionally along a gradient from the habitats typically occupied by the eastern woodchuck, with relatively flat topography and deep soils, to those featuring moderate topography and greater variation in soil depth inhabited by yellow-bellied marmots in the lower portions of the western mountains, and ending in the extremely localized habitat in which the high montane species may be found. For example, $19 \%$ of all burrow systems of the eastern woodchuck located in 40 ha of conterminous ("good") habitat in Ontario were hibernacula, at a density of 0.77 hibernacula/ha (de Vos and Gillespie 1960 ). In our study area, the density of hibernacula was $1.7 /$ ha, comprising $30 \%-50 \%$ of all burrow systems. Thus, the extent and density of hibernacula within favorable habitat may determine the degree of sociality exhibited by a species.

In summary, we suggest that the optional reproductive strategy of a female yellow-bellied marmot includes the utilization of spring fat reserves which are accumulated in the previous growing season, the acquisition of a hibernaculum, and occupancy of a home range where forage appears early in the season. The degree of success of this strategy in any given year is affected by variation in the end of the previous growing season and the start of the current one and probably also by the quality of the hibernaculum.

\section{ACKNOWLEDGMENTS}

This research was supported by grants GB40141X, GB32494, and BMS74-21193 from the National Science Foundation. We thank Dennis Johns, whose efforts provided much of the North Pole Basin weight data, and Jim Honacki, who provided timely field assistance and valuable discussion. This paper is part of a thesis submitted by the senior author to the University of Kansas in partial fulfillment of the requirements for the M.A. degree. 


\section{Literature Cited}

Andersen, D. C. 1975. Socio-ecology of Marmota: Reproductive strategies of female yellow-bellied marmots ( $M$. flaviventris). M.A. Thesis, Univ. Kansas Lawrence. $37 \mathrm{p}$.

$\rightarrow$ Armitage, K. B. 1962. Social behaviour of a colony of the yellow-bellied marmot (Marmota flaviventris). Anim. Behav. 10:319-331.

$\rightarrow$ 1965. Vernal behaviour of the yellow-bellied marmot (Marmota flaviventris). Anim. Behav. 13: $59-68$.

$\rightarrow$ 1973. Population changes and social behavior following colonization by the yellow-bellied marmot J. Mammal. 54:842-854.

$\rightarrow \rightarrow$ 1974. Male behaviour and territoriality in the yellow-bellied marmot. J. Zool. Lond. 172:233-265.

$\rightarrow$ Armitage, K. B., and J. F. Downhower. 1974. De mography of yellow-bellied marmot populations. Ecology 55:1233-1245.

Armitage, K. B., J. F. Downhower and G. E. Svendsen. 1976. (In press) Seasonal changes in weights of marmots. Am. Midl. Nat.

$\rightarrow$ Barash, D. P. 1973a. The social biology of the Olym pic marmot. Anim. Behav. Monogr. 6:171-245.

$\longrightarrow \rightarrow 1973 b$. Social variety in the yellow-bellied marmot (Marmota flaviventris). Anim. Behav. 21: $579-584$

$\longrightarrow$ 1974a. The social behaviour of the hoary marmot (Marmota caligata). Anim. Behav. 22:256261.

$\rightarrow$ 1974b. The evolution of marm

$\rightarrow$ Bliss, L. C. 1962. Caloric and lipid content in alpine tundra plants. Ecology 43:753-757.

de Vos, A., and D. I. Gillespie. 1960. A study of woodchucks on an Ontario farm. Can. Field Nat. 74: $130-145$.

Dixon, W. J. 1968. Biomedical computer programs Univ. of California Publ. Automatic Computation No. 2, University of California Press, Berkeley. 600 p.

Downhower, J. F. 1968. Factors affecting the dispersal of yearling yellow-bellied marmots. Ph.D $\rightarrow$ Thesis, Univ. Kansas, Lawrence. 161 p.

$\rightarrow$ Downhower, J. F., and K. B. Armitage. 1971. The yellow-bellied marmot and evolution of polygamy Am. Nat. 105:355-370.

$\rightarrow$ Freeland, W. J., and D. H. Janzen. 1974. Strategies in herbivory by mammals: The role of plant secondary compounds. Am. Nat. 108:269-289.

Golley, F. B. 1961. Energy values of ecological materials. Ecology 42:581-584.

Hadley, E. B., and L. C. Bliss. 1964. Energy relationships of alpine plants on Mt. Washington, New Hampshire. Ecol. Monogr. 34:331-357.

Kilgore, D. L., Jr. 1972. Energy dynamics of the yellow-bellied marmot (Marmota flaviventris): A hibernator. Ph.D. Thesis. Univ. Kansas, Lawrence. 83 p.

Langenheim, J. H. 1962. Vegetation and environmental patterns in the Crested Butte area, Gunnison County, Colorado. Ecol. Monogr. 32:249-285.

$\rightarrow$ Nee, J. A. 1969. Reproduction in a population of yellow-bellied marmots (Marmota flaviventris) $\mathbf{J}$. Mammal. 50:756-765.

Paine, R. T. 1971. The measurement and application of the calorie to ecological problems. Ann. Rev. Ecol. Syst. 2:145-164.

Pattie, D. L. 1967. Observations on an alpine population of yellow-bellied marmots (Marmota flaviventris). Northwest Sci. 41:96-102.

$\rightarrow$ Rochow, T. F. 1969. Growth, caloric content, and sugars in Caltha leptosepala in relation to alpine snowmelt. Bull. Torrey Bot. Club 96:689-698.

Snedecor, G. W. 1956. Statistical methods. Fifth edition. Iowa State College Press, Ames. 534 p.

Snyder, R. L., and J. J. Christian. 1960. Reproductive cycle and litter size of the woodchuck. Ecology 41: 647-656.

Snyder, R. L., D. E. Davis, and J. J. Christian. 1961. Seasonal changes in the weights of woodchucks. J. Mammal. 42:297-312.

Sokal, R. R., and F. J. Rohlf. 1969. Biometry. W. H. Freeman and Co., San Francisco. 776 p.

Sokal, R. R., and P. H. A. Sneath. 1963. Principles of numerical taxonomy. W. H. Freeman, San Francisco. $359 \mathrm{p}$.

Svendsen, G. E. 1974. Behavioral and environmental factors in the spatial distribution and population dynamics of a yellow-bellied marmot population. Ecololgy 55:760-771.

Svendsen, G. E., and K. B. Armitage. 1973. An application of mirror-image stimulation to field behavioral studies of marmots. Ecology 54:623-627.

Wiegert, R. G. 1962. The selection of an optimum quadrat size for sampling the standing crop of grasses and forbs. Ecology 43:125-129. 